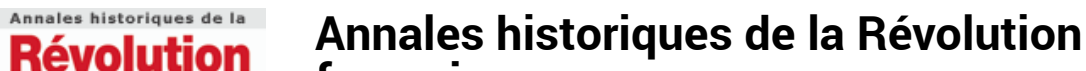

française française

341 | juillet-septembre 2005

Varia

\section{Cultures in Conflict. The French Revolution}

Jean-Luc Chappey

\section{OpenEdition}

Journals

Édition électronique

URL : https://journals.openedition.org/ahrf/2218

DOI : 10.4000/ahrf.2218

ISSN : 1952-403X

Éditeur :

Armand Colin, Société des études robespierristes

Édition imprimée

Date de publication : 1 septembre 2005

Pagination : 184

ISSN : 0003-4436

\section{Référence électronique}

Jean-Luc Chappey, «Cultures in Conflict. The French Revolution», Annales historiques de la Révolution française [En ligne], 341 | juillet-septembre 2005, mis en ligne le 27 avril 2006, consulté le 23 avril 2022. URL : http://journals.openedition.org/ahrf/2218 ; DOI : https://doi.org/10.4000/ahrf.2218

Ce document a été généré automatiquement le 23 avril 2022.

Tous droits réservés 


\title{
Cultures in Conflict. The French Revolution
}

\author{
Jean-Luc Chappey
}

\section{RÉFÉRENCE}

Gregory S. Brown, Cultures in Conflict. The French Revolution, Westport-London, Greenwood Press, 2003, XXIV-212 p., ISBN 0-313-31789-5, 25.99 £.

1 Professeur assistant à l'Université du Nevada (Las Vegas), spécialiste de l'histoire des hommes de lettres et du théâtre des XVII ${ }^{e}$ et $\mathrm{XVIII}^{\mathrm{e}}$ siècles (voir son ouvrage A Field of Honour. Writers, Court Culture, and Public Theater in French Literary Life from Racine to the Revolution, New York, Columbia University Press, 2002), Gregory S. Brown propose ici un manuel original et stimulant sur l'histoire de la Révolution française. Soucieux de proposer une synthèse générale des différents phénomènes qui participent au mouvement révolutionnaire, l'auteur s'intéresse particulièrement aux principales transformations qui affectent les individus et les cadres sociaux et aux divers conflits qu'elles font émerger. Loin de privilégier une histoire politique "vue d'en haut", l'auteur croise, de manière convaincante, différentes échelles d'analyse (de la politique de la rue aux batailles parlementaires, de Paris à la province...) en tentant de prendre en compte les questionnements historiographiques les plus récents. Après une présentation chronologique générale de la période 1787-1799 (chapitre 1) et une analyse synthétique des tensions politiques et des luttes sociales qui caractérisent les dernières décennies de l'Ancien Régime (chapitre 2), G. S. Brown présente la période révolutionnaire à travers cinq grands thèmes: les luttes contre les privilèges et les formes de domination politique et sociale (chapitre 3); les formes de participation politique et la question de la citoyenneté - armée, sociétés politiques, contrerévolution... - (chapitre 4); la question de la justice et de l'ordre social (violence, révoltes populaires, coups d'état...); les finances et l'économie; la vie religieuse et culturelle. Il va sans dire que cette présentation, trop succincte, affaiblit considérablement la variété des approches et des questions soulevées par l'auteur. 
L'analyse de chaque thème repose sur la présentation commentée d'une dizaine de documents parfois peu connus (textes ou images) qui permettent d'approfondir la réflexion et donnent aux lecteurs néophytes la mesure de la diversité des formes de prises de parole et d'intervention publique en Révolution. S'interrogeant particulièrement sur la place du peuple dans le phénomène révolutionnaire, l'auteur présente, dans plusieurs chapitres, l'extrême diversité de sa participation politique et analyse les débats et conflits qu'elle fait naître. Si l'on peut toujours discuter de certaines lacunes ou présentations trop rapides (n'est-ce pas la loi du genre pour un tel ouvrage pédagogique ?), il n'en reste pas moins que ce manuel destiné aux étudiants américains propose une synthèse particulièrement bien documentée qui donne aux lecteurs les clés nécessaires pour appréhender les débats historiographiques les plus récents, aussi bien sur les questions touchant aux diverses formes de violences, aux modalités de la politisation et aux dynamiques de radicalisation des luttes, que sur celles proposées par l'histoire des femmes, de la famille, de la contre-révolution ou par l'histoire des pratiques religieuses et culturelles. En cherchant toujours à croiser les diverses approches, pointant l'attention sur les diverses formes de conflits (politiques, mais aussi religieux, sociaux, économiques ou culturels), l'auteur inscrit sa présentation dans les interrogations et discussions historiographiques actuelles. C'est là en effet l'intérêt de l'ouvrage que de parvenir à présenter de manière claire et rapide un vaste tableau des phénomènes essentiels du processus révolutionnaire en en faisant toujours apparaître la complexité. En dépit de quelques critiques touchant à une bibliographie bien trop simplifiée, on ne saurait trop conseiller la lecture de ce manuel à tous ceux qui souhaitent « entrer » en Révolution. 